\title{
Primary Non-Hodgkin's Lymphoma of Stomach: To Report 54 Patients and Analysis of Major Reported Series
}

\author{
Mansour Ansari, ${ }^{1}$ Hamid Nasrolahi, ${ }^{1}$ Amir Abbas Kani, ${ }^{2}$ Seyed Hasan Hamedi, \\ Samira Razzaghi, ${ }^{2}$ Niloofar Ahmadloo, ${ }^{1}$ Mohammad Mohammadianpanah, ${ }^{3}$ \\ Shahpour Omidvari, ${ }^{1}$ and Ahmad Mosalaei ${ }^{4}$ \\ ${ }^{1}$ Department of Radiation Oncology, Namazi Hospital, Shiraz University of Medical Sciences, Shiraz 71936, Iran \\ ${ }^{2}$ Student Research Committee, Resident of Radiation Oncology, Shiraz University of Medical Sciences, Shiraz 71936, Iran \\ ${ }^{3}$ Colorectal Research Center, Shiraz University of Medical Sciences, Shiraz 71936, Iran \\ ${ }^{4}$ Shiraz Institute for Cancer Research, Shiraz University of Medical Sciences, Shiraz 71936, Iran \\ Correspondence should be addressed to Hamid Nasrolahi; nasrolahihamid@yahoo.com
}

Received 7 May 2013; Revised 21 August 2013; Accepted 20 September 2013

Academic Editor: Umberto Vitolo

Copyright (C) 2013 Mansour Ansari et al. This is an open access article distributed under the Creative Commons Attribution License, which permits unrestricted use, distribution, and reproduction in any medium, provided the original work is properly cited.

\begin{abstract}
Introduction. This study aimed to report the characteristics, prognostic factors, and treatment outcomes of 54 patients with primary gastric lymphoma. Materials and Methods. This retrospective study was carried out by reviewing the medical records of 54 adult patients diagnosed at a tertiary academic hospital. All the patients were treated with curative intent. Forty-four patients (81.5\%) underwent gastrectomy followed by adjuvant chemotherapy and/or radiotherapy, whereas 10 ones (18.5\%) were treated with chemotherapy alone or with radiotherapy. Results. The study was conducted on 25 males and 29 females with the median age of 50 years. Diffuse large B-cell lymphoma (DLCL) (67\%) and Mucosa Associated Lymphoid Tissue (MALT) lymphoma (26\%) were the most common histologic types. Besides, 36 (59\%), 16 (30\%), 5 (9\%), and 1 (2\%) patients were in stages I, II, III, and IV, respectively. The 5-year disease-free survival and overall survival were $64.7 \%$ and $67 \%$, respectively. In univariate analysis for overall survival, International Prognostic Index (IPI) $(P<0.001)$, the WHO performance status $(P<0.001)$, Ann Arbor stage $(P=0.027)$, age $(P=0.034)$, and LDH serum level $(P<0.001)$ were the prognostic factors. Conclusion. Gastric lymphoma tends to present in early stage of the disease and has a favorable outcome.
\end{abstract}

\section{Introduction}

Primary gastric lymphomas are rare. Although their incidence rate is increasing, they comprise less than $10 \%$ of gastric malignancies. Despite this rarity, stomach accounts for more than two-third of all extranodal non-Hodgkin lymphomas. Because of its multiple subtypes and low prevalence, its treatment is not so clear cut. More than 30 types, with different biological and clinical characteristics, have been recognized by the WHO classification. Two main subtypes are MALT and DLCL with different behaviors and treatments. Other less frequent subtypes are follicular, mantle, and T-cell lymphoma [1-3].

Previously, the main treatment for gastric lymphomas was supposed to be surgery. Older studies pointed to the important role of surgery in treatment of the disorder [2, 4]. However, multiple retrospective and prospective studies in late 20th century showed that extend of surgery and even performing the surgery had no roles in gastric lymphoma outcome $[2,3]$. Early stage MALT lymphomas are usually treated with antibiotics. Those who are negative for or resistant to $H$. pylori are treated with radiotherapy. Chemotherapy is also an effective therapeutic option. On the other hand, gastric DLCL is treated by chemotherapy and immunotherapy. Radiotherapy could be used for localized cases. Yet, chemotherapy accompanied by cyclophosphamide, doxorubicin, vincristine, and prednisolone (CHOP) is the most prevalent regimen with acceptable toxicity. There is still no standard treatment and the general trend is toward less aggressive and more conservative modalities $[3,4,30,37,40]$. 
TABLE 1: Distribution of treatment schedules and histopathologic types in 54 patients with primary gastric lymphoma.

\begin{tabular}{|c|c|c|c|c|c|c|}
\hline \multirow{2}{*}{ Treatment } & \multicolumn{6}{|c|}{ Histopathology } \\
\hline & DLBCL & MALT lymphoma & Follicular lymphoma & T-cell lymphoma & Mantel cell lymphoma & Total \\
\hline Sur $\rightarrow$ RT & 0 & 2 & 0 & 0 & 0 & 2 \\
\hline Sur $\rightarrow \mathrm{RT} \rightarrow \mathrm{ChT}$ & 3 & 2 & 0 & 0 & 0 & 5 \\
\hline $\mathrm{Sur} \rightarrow \mathrm{ChT} \rightarrow \mathrm{RT}$ & 19 & 6 & 1 & 0 & 1 & 27 \\
\hline $\mathrm{Sur} \rightarrow \mathrm{ChT} \rightarrow \mathrm{RT} \rightarrow \mathrm{ChT}$ & 1 & 1 & 0 & 0 & 0 & 2 \\
\hline Sur $\rightarrow$ ChT & 5 & 1 & 0 & 2 & 0 & 8 \\
\hline $\mathrm{ChT} \rightarrow \mathrm{RT}$ & 6 & 1 & 0 & 0 & 0 & 7 \\
\hline $\mathrm{ChT} \rightarrow \mathrm{RT} \rightarrow \mathrm{ChT}$ & 1 & 1 & 0 & 0 & 0 & 2 \\
\hline ChT alone & 1 & 0 & 0 & 0 & 0 & 1 \\
\hline Total & 36 & 14 & 1 & 2 & 1 & 54 \\
\hline
\end{tabular}

DLBCL: diffuse large B-cell lymphoma; Sur: surgery; RT: radiotherapy; ChT: chemotherapy.

In this study, all the patients were referred to us from surgery, gastroenterology, or hematology oncology wards, and we had no access to prior treatments, such as antibiotic therapy.

In general, the prognosis depends on multiple factors, such as patient's age and performance status, histologic subtype, treatment, lactate dehydrogenase $(\mathrm{LDH})$ serum levels, and disease related factors $[1,5]$. This study aims to report the characteristics, prognostic factors, and treatment outcomes of 54 patients with primary gastric lymphoma and analyze the major reported series.

\section{Materials and Methods}

The present retrospective study was conducted on the patients with gastric lymphoma in our referral radiotherapy center between 1998 and 2010. All the patients had presented with gastrointestinal complaint, and lymphoma diagnosis was made by endoscopy biopsy first. The patients' demographic characteristic, disease factors (size, location, histology, etc.), performance status, treatment (operation, radiotherapy/chemotherapy technique, and dose), and outcome (disease-free survival and overall survival) were obtained from their records and by phone if needed. We searched "PubMed" using "gastric and lymphoma" or "stomach and lymphoma" to find the related papers.

2.1. Patients' and Disease Characteristics. This study was conducted on 54 cases with biopsy proven diagnosis of primary gastric NHL who had been treated and followed up at our ward during 1998 to 2010. The performance status (PS) was determined according to the World Health Organization (WHO) scale. Only the patients who had initially presented with gastric lymphoma were classified as gastric lymphoma, and those with secondary gastric involvement with lymphoma were excluded from the study. The patients were staged according to the Ann Arbor staging system at the time of diagnosis. All the patients had undergone endoscopy and location of tumor was mentioned at reports. However, no information was available regarding $H$. pylori status and previous treatment if performed. Tumor sizes were registered in the operation notes or imaging, pathology, or endoscopy reports. Tumors with above $5 \mathrm{~cm}$ maximum diameter were defined as bulky disease. The location of the tumor at the stomach and diffuse gastric involvement were also determined.

2.2. Clinical Investigation. Clinical investigation included history, physical examination, complete blood count, erythrocyte sedimentation rate, kidney function test, liver function test, serum LDH, abdomen and pelvic ultrasonography, Computed Tomography (CT) scan, chest X ray, bone marrow aspiration, and biopsy.

2.3. Treatment. All the patients were treated with curative intent. Overall, 44 patients $(81.5 \%)$ had undergone gastrectomy followed by adjuvant chemotherapy and/or radiotherapy, whereas 10 ones $(18.5 \%)$ had been treated with chemotherapy alone or with radiotherapy (see Table 1). In all the patients, chemotherapy included $\mathrm{CHOP}$ regimen (cyclophosphamide $750 \mathrm{mg} / \mathrm{m}^{2}$, doxorubicin $50 \mathrm{mg} / \mathrm{m}^{2}$, vincristine $1.4 \mathrm{mg} / \mathrm{m}^{2}$, prednisolone $100 \mathrm{mg}$ ). It should be mentioned that none of our patients, even those in the later period of the study, received rituximab. Radiotherapy consisted of external beam conventional technique with megavoltage linear accelerator or Cobalt-60 photons, and a median total dose of 31 (range 9-54) Gy was delivered.

2.4. Statistical Analysis. Disease- or progression-free survival was calculated as the duration from the date of histological diagnosis to the date of relapse or disease progression or censored at the date of the last followup. In addition, OS was calculated as the duration from the date of histological diagnosis to the date of death resulting from any cause or censored at the date of the last followup. Univariate analysis for DFS and OS rates were performed using the Kaplan-Meier method and the prognostic factors were compared using the log-rank test. Besides, multiple-covariate analysis was performed using the stepwise regression hazards regression model. The Hazard Ratio (HR) for death, with the 95\% Confidence Interval (CI), was calculated for the variable groups. The stratified log-rank test was used to compare the treatment results in each variable group. A $P$ value of 0.05 or less was considered as statistically significant. 


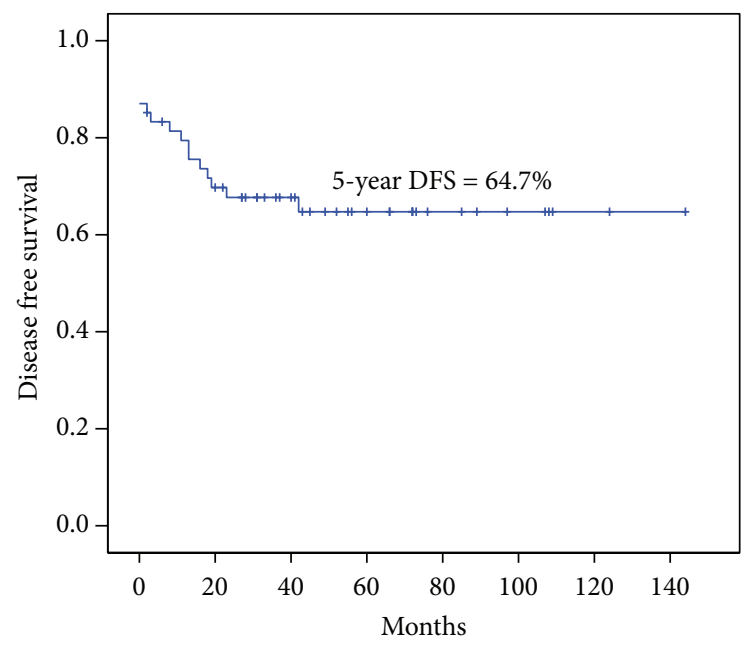

FIGURE 1

\section{Results}

3.1. Patients and Clinical Characteristics. A total of 54 patients with primary gastric lymphoma were reviewed. The patients' median age was 50 (17-75) years, and 28 patients (51\%) were 50 years old or younger. Besides, the peak age was during the sixth decade of life in both sexes. The WHO performance status was 0 or 1 in approximately $83 \%$ of the patients, while 2 or 3 in 13\%. Epigastric pain and discomfort (83\%), anorexia and weight loss (41\%), and postprandial vomiting (28\%) were the most common presenting signs and symptoms. B symptoms occurred in $33 \%$ of the patients. In addition, bulky disease (primary tumor size more than $10 \mathrm{~cm}$ in the greatest diameter) was documented in 20 patients $(37 \%)$. According to the pathologic, imaging, and clinical findings, $36(59 \%), 16(30 \%), 5(9 \%)$, and $1(2 \%)$ patients were in stages I, II, III, and IV, respectively. Diffuse large B-cell lymphoma (67\%) and Mucosa Associated Lymphoid Tissue (MALT) lymphoma (26\%) were the most common histological types. Table 1 represents the distribution of the treatment schedules and histopathological subtypes. Most patients, including 19 patients with DLCL and 6 ones with MALT lymphoma, were treated with surgery and followed by chemotherapy and radiotherapy. Most patients were referred to us from gastrointestinal ward or hematology ward, and we had no information on prior antibiotic treatment if it has been done. The total 5-year disease-free survival and overall survival were $64.7 \%$ and $67 \%$, respectively (Figures 1 and 2).

3.2. Prognostic Factors. All the potential prognostic variables, including the WHO performance status, age, sex, Ann Arbor stage of disease, primary tumor size and location, B symptoms, histologic grade, serum LDH level, treatment modality, dose of radiation, and International Prognostic Index (IPI), were analyzed to find out their impacts on disease-free survival and overall survival of the patients with gastric lymphoma (Table 2). A modified IPI including four prognostic factors (performance status, age, stage, and serum $\mathrm{LDH}$ level) was considered in this study. In univariate analysis for

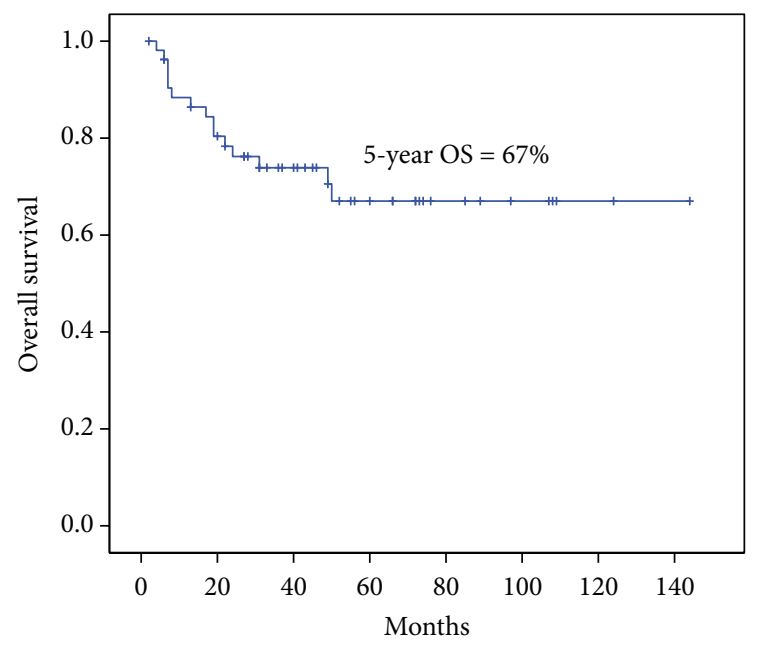

Figure 2

overall survival in all patients, IPI $(P<0.001)$, WHO performance status $(P<0.001)$, Ann Arbor stage $(P=0.027)$, age $(P=0.034)$, and LDH serum level $(P<0.001)$ were the prognostic factors (Table 2 ). These factors were also separately analyzed in DLCL and MALT lymphoma by stratified logrank test (Table 3). However, in multivariate analysis using the stepwise logistic regression model, only modified IPI ( $P=$ $0.001, \mathrm{HR}=7.53$, and $95 \% \mathrm{CI}=1.619-35.065)$ and the $\mathrm{WHO}$ performance status $(P=0.01, \mathrm{HR}=3.00$, and $95 \% \mathrm{CI}=$ 1.599-5.630) were independent prognostic factors for overall survival.

\section{Discussion}

This retrospective study has been conducted at the Nemazee hospital, the referral center in south of Iran. This study is the first report on GL in Iran. In this study multiple factors, including gender, age, grade, surgery, and LDH level (Table 4), have been proposed as prognostic factors. Some of these prognostic factors are disease related and some are patient related. Some authors believe that prognostic factors are more important than the treatment schedule for survival [5].

Mean age in our study was 50 (17-75) years. As seen in Table 5, other studies showed similar results. Although in some studies age was a prognostic factor, we found no relation between it and outcome [6-8]. Most of our patients were females. Results in other studies are inhomogenous. Although it was a prognostic factor in 1 study, others including the present study revealed no relation [7].

Extranodal lymphoma consists of $25-40 \%$ of all lymphomas. The most common location for extranodal lymphoma is the gastrointestinal tract which consists of $30-40 \%$ of the extranodal lymphoma [2,37]. Gastric Lymphoma (GL) consists of $1-7 \%$ of stomach malignancies and is an older population disease $[1,3]$. Primary GL is not so common, but the stomach is the most common site for extranodal lymphoma, and its incidence is increasing $[3,6,37]$. 
TABLE 2: Univariate analysis of prognostic factors for clinical outcome.

\begin{tabular}{|c|c|c|c|c|c|}
\hline Prognostic factors & Patients' number & 5-year DFS (\%) & $P$ value & 5-year OS (\%) & $P$ value \\
\hline \multicolumn{6}{|l|}{ WHO performance score } \\
\hline $0-1$ & 45 & 73.9 & \multirow{3}{*}{$<0.001$} & 76.2 & \multirow{3}{*}{$<0.001$} \\
\hline 2 & 5 & 00.0 & & 00.0 & \\
\hline 3 & 4 & 00.0 & & 00.0 & \\
\hline \multicolumn{6}{|l|}{ Sex } \\
\hline Female & 29 & 61.8 & \multirow{2}{*}{0.742} & 66.8 & \multirow{2}{*}{0.923} \\
\hline Male & 25 & 68.1 & & 67.3 & \\
\hline \multicolumn{6}{|l|}{ Age } \\
\hline$\leq 50$ years & 28 & 73.9 & \multirow{2}{*}{0.097} & 79.6 & \multirow{2}{*}{0.034} \\
\hline$>50$ years & 26 & 55.2 & & 49.1 & \\
\hline \multicolumn{6}{|l|}{ Ann Arbor stage } \\
\hline I & 33 & 73.2 & \multirow{4}{*}{0.071} & 75.1 & \multirow{4}{*}{0.027} \\
\hline II & 15 & 59.5 & & 70.1 & \\
\hline III & 5 & 40.0 & & 25.0 & \\
\hline IV & 1 & 00.0 & & 00.0 & \\
\hline \multicolumn{6}{|l|}{ Histology } \\
\hline DLBC & 36 & 61.2 & \multirow{3}{*}{0.645} & 59.5 & \multirow{3}{*}{0.405} \\
\hline MALT & 14 & 71.4 & & 77.9 & \\
\hline Others & 4 & 100.0 & & 100.0 & \\
\hline \multicolumn{6}{|l|}{ Primary tumor size } \\
\hline $1-5 \mathrm{~cm}$ & 13 & 61.5 & \multirow{3}{*}{0.412} & 75.0 & \multirow{3}{*}{0.182} \\
\hline $6-9 \mathrm{~cm}$ & 21 & 72.8 & & 75.9 & \\
\hline$\geq 10 \mathrm{~cm}$ & 20 & 58.9 & & 50.5 & \\
\hline \multicolumn{6}{|l|}{ B symptoms } \\
\hline No & 36 & 78.8 & \multirow{2}{*}{0.001} & 77.8 & \multirow{2}{*}{0.013} \\
\hline Yes & 18 & 36.4 & & 40.6 & \\
\hline Serum LDH level & & & & & \\
\hline Normal & 34 & 93.1 & $<0.001$ & 92.6 & $<0.001$ \\
\hline Elevated & 20 & 28.7 & & 34.0 & \\
\hline Histological grade & & & & & \\
\hline I & 27 & 64.0 & & 66.4 & \\
\hline II & 13 & 69.2 & 0.977 & 76.2 & 0.951 \\
\hline III & 14 & 64.3 & & 61.9 & \\
\hline Treatment modality & & & & & \\
\hline Surgery $+\mathrm{CT} \pm \mathrm{RT}$ & 44 & 61.5 & 0.387 & 64.7 & 0.606 \\
\hline $\mathrm{CT}$ and/or RT & 10 & 80.0 & & 80.0 & \\
\hline Radiation dose & & & & & \\
\hline No RT & 7 & 34.3 & & 41.7 & \\
\hline$<30 \mathrm{~Gy}$ & 11 & 61.4 & 0.236 & 47.7 & 0169 \\
\hline $30-40$ Gy & 26 & 75.4 & & 80.7 & \\
\hline$>40 \mathrm{~Gy}$ & 10 & 60.0 & & 60.0 & \\
\hline IPI & & & & & \\
\hline 0-1 risk factor & 35 & 84.4 & & 89.2 & \\
\hline 2 risk factor & 6 & 33.3 & $<0.001$ & 25.0 & $<0.001$ \\
\hline$\geq 3$ risk factor & 13 & 16.2 & & 13.6 & \\
\hline Location & & & & & \\
\hline Proximal & 27 & 67.3 & & 72.1 & \\
\hline Distal & 24 & 61.4 & 0.791 & 61.7 & 0.623 \\
\hline Diffuse involvement & 3 & 66.7 & & 66.7 & \\
\hline All patients & 54 & 64.7 & & 67.0 & - \\
\hline
\end{tabular}

DFS: disease-free survival; OS: overall survival; CT: chemotherapy; RT: radiotherapy; IPI: International Prognostic Index. 
TABLE 3: The stratified log-rank test analysis of prognostic factors for histologic subtypes.

\begin{tabular}{|c|c|c|c|c|}
\hline \multirow{2}{*}{ Prognostic factors } & \multirow{2}{*}{ Patients' number } & \multicolumn{2}{|c|}{ 5-year OS (\%) } & \multirow{2}{*}{$P$ value } \\
\hline & & DLBC & MALT & \\
\hline \multicolumn{5}{|l|}{ WHO performance score } \\
\hline $0-1$ & 45 & 67.0 & 90.9 & \multirow{3}{*}{$<0.001$} \\
\hline 2 & 5 & 00.0 & 00.0 & \\
\hline 3 & 4 & 00.0 & 50.0 & \\
\hline \multicolumn{5}{|l|}{ Sex } \\
\hline Female & 29 & 59.8 & 72.9 & \multirow{2}{*}{0.985} \\
\hline Male & 25 & 58.6 & 83.3 & \\
\hline \multicolumn{5}{|l|}{ Age } \\
\hline$\leq 50$ years & 28 & 74.9 & 88.9 & \multirow{2}{*}{0.021} \\
\hline$>50$ years & 26 & 36.2 & 60.0 & \\
\hline \multicolumn{5}{|l|}{ Ann Arbor stage } \\
\hline I & 33 & 64.7 & 90.0 & \multirow{3}{*}{0.039} \\
\hline II & 15 & 73.3 & 50.0 & \\
\hline III-IV & 6 & 00.0 & 50.0 & \\
\hline \multicolumn{5}{|l|}{ Primary tumor size } \\
\hline $1-5 \mathrm{~cm}$ & 13 & 57.1 & - & \multirow{3}{*}{0.107} \\
\hline $6-9 \mathrm{~cm}$ & 21 & 72.1 & - & \\
\hline$\geq 10 \mathrm{~cm}$ & 20 & 63.6 & 57.1 & \\
\hline \multicolumn{5}{|l|}{ B symptoms } \\
\hline No & 36 & 73.2 & 81.8 & \multirow{2}{*}{0.025} \\
\hline Yes & 18 & 35.4 & 66.7 & \\
\hline \multicolumn{5}{|l|}{ Serum LDH level } \\
\hline Normal & 34 & 94.7 & 87.5 & \multirow{2}{*}{$<0.001$} \\
\hline Elevated & 20 & 21.4 & 66.7 & \\
\hline \multicolumn{5}{|l|}{ Treatment modality } \\
\hline Surgery + CT $\pm \mathrm{RT}$ & 44 & 53.8 & 82.5 & \multirow{2}{*}{0.502} \\
\hline $\mathrm{CT}$ and/or RT & 10 & 87.5 & 50.0 & \\
\hline \multicolumn{5}{|l|}{ IPI } \\
\hline $0-1$ risk factor & 35 & 87.0 & 90.9 & \multirow{3}{*}{$<0.001$} \\
\hline 2 risk factor & 6 & 20.0 & - & \\
\hline$\geq 3$ risk factor & 13 & 00.0 & 33.3 & \\
\hline All patients & 54 & 59.5 & 77.9 & 0.405 \\
\hline
\end{tabular}

DFS: disease-free survival; OS: overall survival; CT: chemotherapy; RT: radiotherapy; IPI: International Prognostic Index.

In general, GL more frequently involves antrum, corpus, and cardia [3]. In our study, most of the patients (50\%) had primary lesion in the proximal half and tumor location was not related to the outcome. Most of lesions in our study were larger than $5 \mathrm{~cm}$. Tumor sizes were not associated with better or worse outcomes, but Economopoulos showed that there may be a relation [9]. Staging in our study was performed according to the Ann Arbor system. Most of our cases were in stages I and II (65\% and 28\%, resp.), and only 1 patient was in stage IV. As shown in Table 4 stage was a significant prognostic factor in multiple studies $[8,10-14]$. But we found a relation in univariate analysis not in multivariate analysis.

Rise in LDH level, BM involvement, and B symptoms are less frequent in GL $[34,37]$. In our series, 34 patients had normal LDH levels and their 5-year disease-free survival and overall survival were significantly improved $(P$ value $<0.001)$. Although some studies have shown no relationships between
LDH level and survival, abnormally elevated LDH level was a prognostic factor in our study $[5,11,15,16,35]$.

IPI consists of some prognostic factors, such as age $>60$ years, stage $>$ II2, high LDH level, ECOG PS > 2, and more than one Extranodal Site (EN) of disease. Our study results indicated a significant relationship between IPI and survival. IPI has been proposed as the strongest prognostic factor [15, 38]; however, some studies have reported this factor not to have any effects on survival $[7,35]$.

The most common subtype in our study was DLCL followed by MALT. T-cell, mantle, and follicular lymphomas totally were detected in 4 cases. Survivals in different subtypes were not statistically different. Up to now, over 30 subtypes of GL with various prognoses have been recognized by the WHO classification, and the disease treatment is guided by the subtype $[1,3]$. Different studies have reported MALT and DLCL as the most common types $[2,17,39]$. In our study as 
TABLE 4: Survival rates and prognostic factors in patients with primary gastric lymphoma in the literature.

\begin{tabular}{|c|c|c|c|c|c|}
\hline Author [ref] & Patients' number & 5-year DFS (\%) & 3-year OS (\%) & 5-year OS (\%) & Prognostic factor \\
\hline Medina-Franco et al. [5] & 41 & 52.5 & - & 71.2 & LDH serum level, PS \\
\hline Danzon et al. [6] & 361 & - & 63 & 61 & Age \\
\hline Park et al. [7] & 214 & - & - & - & Age, LDH serum level, gender, ascites \\
\hline Bani-Hani et al. [8] & 19 & - & - & 48.2 & Age, stage \\
\hline Economopoulos et al. [9] & 29 & - & - & 58 & Stage, size \\
\hline Tanaka et al. [10] & 95 & - & 81.7 & - & Stage, LDH serum level \\
\hline Huang et al. [11] & 83 & 52 & - & 59 & PS, stage, modified IPI \\
\hline Muller et al. [12] & 45 & - & - & 40 & Grade, stage \\
\hline Mäkelä et al. [13] & 32 & - & - & 56 & Stage, radical surgery, age \\
\hline Xue et al. [14] & 83 & - & - & 77.8 & $\begin{array}{l}\text { Lymph node involvement and clinical } \\
\text { stage }\end{array}$ \\
\hline Brincker and D’Amore [15] & 106 & - & - & 67 & LDH serum level, fever \\
\hline Luo et al. [16] & 68 & 75.7 & 78.2 & 75.7 & Surgery \\
\hline Barreda et al. [17] & 169 & - & 61.34 & - & IPI, HDL, remission, treatment, location \\
\hline Durr et al. [18] & 35 & 90 & - & - & Grade \\
\hline Shaw et al. [19] & 62 & - & - & - & $\begin{array}{l}\text { Weight loss, invasion of adjacent organs, } \\
\text { nonsurgical treatment }\end{array}$ \\
\hline Al-Bahrani et al. [20] & 32 & - & - & - & Stage, resectability \\
\hline Salvagno et al. [21] & 525 & - & - & 65.4 & Surgery \\
\hline Jaser et al. [22] & 66 & - & - & - & Stage \\
\hline Present study & 54 & 64.7 & - & 67 & IPI, LDH serum level \\
\hline
\end{tabular}

TABLE 5: Characteristics of some major reported series of primary gastric lymphoma in the literature.

\begin{tabular}{|c|c|c|c|c|c|c|}
\hline Author [ref] & Country & Year & Patients' number & Median age (range) & Male/female ratio & $\begin{array}{l}\text { Most frequent } \\
\text { histological type }\end{array}$ \\
\hline Medina-Franco et al. [5] & Mexico & $1990-2000$ & 41 & 52.6 & 0.86 & Large cell lymphoma \\
\hline Danzon et al. [6] & France & 1989-1997 & 361 & - & 1.24 & High grade \\
\hline Park et al. [7] & Republic of Korea & 1990-2004 & 214 & $55(21-81)$ & 1.27 & Only high grade \\
\hline Bani-Hani et al. [8] & Jordan & $1991-2002$ & 19 & - & - & DLCL \\
\hline Economopoulos et al. [9] & Greece & $1977-1983$ & 29 & $55(21-74)$ & 2.2 & Diffuse histiocytic \\
\hline Huang et al. [11] & China & 2001-2008 & 83 & $52(15-81)$ & 1.18 & DLCL \\
\hline Muller et al. [12] & UK & 1973-1992 & 45 & $65(25-84)$ & 1.5 & High grade \\
\hline Luo et al. [16] & China & $1990-2003$ & 68 & $50(25-82)$ & 1.93 & - \\
\hline Barreda et al. [17] & Peru & $1995-2000$ & 169 & - & 0.83 & DLCL \\
\hline Durr et al. [18] & USA & 1975-1991 & 35 & 63 & - & DLCL \\
\hline Lybeert et al. [23] & The Netherlands & 1982-1992 & 81 & $69.7(30-88)$ & - & Intermediate grade \\
\hline Parvez et al. [24] & Saudi Arabia & 1990-1998 & 22 & - & - & DLCL \\
\hline Schmidt et al. [25] & Germany & $1985-2000$ & 92 & $60(29-85)$ & - & DLCL \\
\hline Shaw et al. [19] & New Zealand & 1969-1987 & 62 & - & 0.87 & - \\
\hline Takahashi et al. [26] & Japan & 1974-1996 & 85 & 60.5 & 1.07 & - \\
\hline Aoyagi et al. [27] & Japan & 1980-1994 & 25 & $59.6(26-89)$ & 0.92 & - \\
\hline Waisberg et al. [28] & Brazil & $1973-2001$ & 16 & $62.8(40-83)$ & 3 & Low grade \\
\hline Koch et al. [29] & Germany & 1996-2004 & 398 & $63.2(20-83)$ & 1.2 & DLCL \\
\hline Al-Bahrani et al. [20] & Iraq & $1965-1978$ & 32 & $42.6(12-70)$ & 2.5 & PDLL \\
\hline Present study & Iran & 1998-2012 & 54 & $50(17-75)$ & 0.86 & DLBCL \\
\hline
\end{tabular}

DLCL: diffuse large cell lymphoma; DLBCL: diffuse large B-cell lymphoma; PDLL: poorly differentiated lymphocytic lymphoma; DFS: disease-free survival; OS: overall survival; LDH: lactic dehydrogenase. 
TABLE 6: Major reports on gastric MALT.

\begin{tabular}{lccccccc}
\hline Author & Country & Stage & Years & Number & Median age (range) & M/F & Survival \\
\hline Andriani et al. [30] & Italy & I-II & $1993-2006$ & 60 & $60(23-80)$ & 1.2 & $94.7(74.6) \% 5 y$ \\
Gisbert et al. [31] & Spain & I-IV & $1991-2005$ & 37 & 61 & 1.63 & NM \\
Park et al. [32] & Republic of Korea & I & $1998-2002$ & 11 & $55.7(36-73)$ & 0.83 & NM \\
Stathis et al. [33] & Italy & I-II & $1990-2006$ & 105 & $64(20-94)$ & 1.05 & $92 \%$ \\
Present study & Iran & I-IV & $1998-2010$ & 14 & $47.50(17-75)$ & 0.75 & 77.95 Y DFS \\
\hline
\end{tabular}

NM: not mentioned.

TABLE 7: Major reports on gastric DLCL.

\begin{tabular}{|c|c|c|c|c|c|c|c|}
\hline Author & Country & Stage & Years & Number & Median age (range) & $\mathrm{M} / \mathrm{F}$ & Survival \\
\hline Tanaka et al. [10] & Japan & I-IV & 1995-2009 & 95 & $68(32-86)$ & 1.11 & - \\
\hline \multirow[t]{2}{*}{ Leopardo et al. [34] } & Italy & I-IV & $2000-2007$ & 30 & 58 & 1.5 & $100 \% 5$ y DFS \\
\hline & & & & 30 & & & $73.3 \%$ \\
\hline Ibrahim et al. [35] & Saudi Arabia & I-IV & $1982-1998$ & 185 & $54(17-94)$ & 1.34 & $68 \% 5$ y OS \\
\hline Spectre et al. [36] & Israel & I-IV & 1990-2005 & 73 & $57(20-80)$ & 1.28 & $62 \% 3 \mathrm{OS}$ \\
\hline Present study & Iran & I-IV & $1998-2010$ & 36 & $49(17-74)$ & 1.0 & 59.55 Y DFS \\
\hline
\end{tabular}

in others, most common subtypes were MALT and DLCL, Table 1. Subtype in some studies was a prognostic factor, however, our study findings revealed no difference among the subtypes regarding the survival rate (Table 3 ). Some studies have evaluated MALT or DLCL alone and are mentioned in Tables 6 and 7.

GL treatment is not so clear and multiple strategies have been proposed in this regard; however, it is not known which one is more beneficial [5]. As Table 1 depicts, most of our patients were operated on and received chemotherapy and radiotherapy afterwards. Chemotherapy in our study included CHOP without rituximab. Rituximab is recently covered by the insurance system. However, none of our 54 patients could afford this agent. In the previous decades, surgical tumor removal and surgical abdominal staging were important parts of the treatment [37]. Surgery was supposed to be necessary, but several studies showed that surgery might not have an essential role and conservative treatment had the same cure rate with fewer side effects $[4,41]$. Most of our patients (44 cases or $81 \%$ ) had undergone surgery before referral to our ward. These patients were those who had received treatment in the early years of this study. These patients had a shorter survival (61.5 months versus 80.0 months).

Rituximab is a monoclonal antibody against CD20 on Bcell lymphoma. It is widely used and is effective in overall survival as well as disease-free survival in nodal lymphoma. Studies on the effectiveness of rituximab in gastric DLCL have revealed improvement in the response rate and survival [10, 34]. This agent is also effective in gastric MALT lymphoma [42]. On the other hand, Aviles in a retrospective study on 42 patients who were affected by stages IE-IIE GL reported the 5year disease-free survival and overall survival as 95\%. In that study, CHOP and rituximab were administered for 6 cycles and comparing to historical reports, no survival benefit was observed [43]. In this study, none of the patients was treated with rituximab.

\section{Conclusion}

GL is a diverse category according to its subtypes and associated prognostic factors. Thus, further prospective studies according to each subtype may open the horizons.

\section{Acknowledgments}

The Research Improvement Center of Shiraz University of Medical Sciences and Ms. A. Keivanshekouh are appreciated for improving the use of English in the paper.

\section{References}

[1] D. H. Roukos, C. Hottenrott, A. Encke, G. Baltogiannis, and D. Casioumis, "Primary gastric lymphomas: a clinicopathologic study with literature review," Surgical Oncology, vol. 3, no. 2, pp. 115-125, 1994.

[2] L. Xie, L. D. Shen, C. Qing et al., "Correlational study of vascular endothelial growth factor expression and microvessel density in primary malignant gastric lymphoma," Medical Oncology, vol. 29, no. 3, pp. 1711-1715, 2012.

[3] P. F. Ferrucci and E. Zucca, "Primary gastric lymphoma pathogenesis and treatment: what has changed over the past 10 years?" British Journal of Haematology, vol. 136, no. 4, pp. 521-538, 2007.

[4] W. Fischbach, "Long-term follow-up of gastric lymphoma after stomach conserving treatment," Best Practice \& Research Clinical Gastroenterology, vol. 24, no. 1, pp. 71-77, 2010.

[5] H. Medina-Franco, S. S. Germes, and C. L. Maldonado, "Prognostic factors in primary gastric lymphoma," Annals of Surgical Oncology, vol. 14, no. 8, pp. 2239-2245, 2007.

[6] A. Danzon, A. Belot, M. Maynadié et al., "Incidence and survival of gastric non-Hodgkin's lymphoma: a population-based study from the Association of the French Cancer Registries (FRANCIM)," Acta Oncologica, vol. 48, no. 7, pp. 977-983, 2009.

[7] Y. H. Park, W. S. Kim, S. M. Bang et al., "Prognostic factor analysis and proposed prognostic model for conventional treatment of high-grade primary gastric lymphoma," European Journal of Haematology, vol. 77, no. 4, pp. 304-308, 2006. 
[8] K. E. Bani-Hani, R. J. Yaghan, and I. I. Matalka, "Primary gastric lymphoma in Jordan with special emphasis on descriptive epidemiology," Leukemia and Lymphoma, vol. 46, no. 9, pp. 1337-1343, 2005.

[9] T. Economopoulos, C. Alexopoulos, N. Stathakis et al., "Primary gastric lymphoma-the experience of a general hospital," British Journal of Cancer, vol. 52, no. 3, pp. 391-397, 1985.

[10] T. Tanaka, K. Shimada, K. Yamamoto et al., "Retrospective analysis of primary gastric diffuse large B cell lymphoma in the rituximab era: a multicenter study of 95 patients in Japan," Annals of Hematology, vol. 91, no. 3, pp. 383-390, 2012.

[11] J. Huang, W. Jiang, R. Xu et al., "Primary gastric non-Hodgkin's lymphoma in Chinese patients: clinical characteristics and prognostic factors," BMC Cancer, vol. 10, article 358, 2010.

[12] A. F. Muller, A. Maloney, D. Jenkins et al., "Primary gastric lymphoma in clinical practice 1973-1992," Gut, vol. 36, no. 5, pp. 679-683, 1995.

[13] J. Mäkelä, T. Karttunen, H. Kiviniemi, and S. Laitinen, "Clinicopathological features of primary gastric lymphoma," Journal of Surgical Oncology, vol. 70, no. 2, pp. 78-82, 1999.

[14] L.-Y. Xue, N. Lü, A.-D. Li et al., "A clinicopathological analysis of gastric lymphoma," Chinese Journal of Pathology, vol. 34, no. 6, pp. 332-336, 2005 (Chinese).

[15] H. Brincker and F. D’Amore, "A retrospective analysis of treatment outcome in 106 cases of localized gastric non-Hodgkin lymphomas," Leukemia and Lymphoma, vol. 18, no. 3-4, pp. 281288, 1995.

[16] Z.-G. Luo, F.-Y. Feng, P. Zhang, X.-Y. Wang, and Q.-L. Wang, "Clinical analysis of 68 patients with primary gastric lymphoma," Chinese Journal of Cancer, vol. 23, no. 12, pp. 1692-1695, 2004 (Chinese).

[17] B. F. Barreda, P. R. Gómez, L. D. Quispe et al., "Primary gastric lymphoma," Revista de Gastroenterología del Perú, vol. 24, no. 3, pp. 238-262, 2004.

[18] E. D. Durr, J. A. Bonner, J. G. Strickler et al., "Management of stage IE primary gastric lymphoma," Acta Haematologica, vol. 94, no. 2, pp. 59-68, 1995.

[19] J. H. F. Shaw, R. G. Douglas, and H. McIntyre, "Primary gastric lymphoma in Auckland, New Zealand," Australian and New Zealand Journal of Surgery, vol. 59, no. 4, pp. 325-328, 1989.

[20] Z. Al-Bahrani, H. Al-Mondhiry, and F. Bakir, "Primary gastric lymphoma. Review of 32 cases from Iraq," Annals of the Royal College of Surgeons of England, vol. 64, no. 4, pp. 234-237, 1982.

[21] L. Salvagno, M. Sorarù, M. Busetto et al., "Gastric non-Hodgkin's lymphoma: analysis of 252 patients from a multicenter study," Tumori, vol. 85, no. 2, pp. 113-121, 1999.

[22] N. Jaser, A. Sivula, and K. Franssila, "Primary gastric nonHodgkin's lymphoma in Finland, 1972-1977. Clinical presentation and results of treatment," Scandinavian Journal of Gastroenterology, vol. 25, no. 10, pp. 1052-1059, 1990.

[23] M. L. M. Lybeert, W. De Neve, L. W. Vrints, V. Coen, and J. W. W. Coebergh, "Primary gastric non-Hodgkin's lymphoma stage IE and IIE," European Journal of Cancer Part A, vol. 32, no. 13, pp. 2306-2311, 1996.

[24] T. Parvez, A. Behani, and A. Ali, "Primary gastric lymphoma," Journal of the College of Physicians and Surgeons Pakistan, vol. 17, no. 1, pp. 36-40, 2007.

[25] W.-P. Schmidt, N. Schmitz, and R. Sonnen, "Conservative management of gastric lymphoma: the treatment option of choice," Leukemia and Lymphoma, vol. 45, no. 9, pp. 1847-1852, 2004.
[26] I. Takahashi, Y. Maehara, T. Koga et al., "Role of surgery in the patients with stage I and II primary gastric lymphoma," HepatoGastroenterology, vol. 50, no. 51, pp. 877-882, 2003.

[27] K. Aoyagi, K. Koufuji, S. Yano et al., "Primary gastric lymphoma: a clinicopathological study," Kurume Medical Journal, vol. 47, no. 2, pp. 97-103, 2000.

[28] J. Waisberg, E. A. André, M. I. F. Franco, J. Z. Abucham-Neto, D. Wickbold, and F. S. Goffi, "Curative resection plus adjuvant chemotherapy for early stage primary gastric non-Hodgkin's lymphoma: a retrospective study with emphasis on prognostic factors and treatment outcome," Arquivos de Gastroenterologia, vol. 43, no. 1, pp. 30-36, 2006.

[29] P. Koch, A. Probst, W. E. Berdel et al., "Treatment results in localized primary gastric lymphoma: data of patients registered within the German multicenter study (GIT NHL 02/96)," Journal of Clinical Oncology, vol. 23, no. 28, pp. 7050-7059, 2005.

[30] A. Andriani, A. Miedico, L. Tedeschi et al., "Management and long-term follow-up of early stage $\mathrm{H}$. pylori-associated gastric MALT-lymphoma in clinical practice: an Italian, multicentre study," Digestive and Liver Disease, vol. 41, no. 7, pp. 467-473, 2009.

[31] J. P. Gisbert, B. Aguado, M. Luna et al., "Gastric MALT lymphoma: clinical characteristics and prevalence of $\mathrm{H}$. pylori infection in a series of 37 cases," Revista Espanola de Enfermedades Digestivas, vol. 98, no. 9, pp. 655-665, 2006.

[32] H. S. Park, Y. J. Kim, W. I. Yang, C. O. Suh, and Y. C. Lee, "Treatment outcome of localized Helicobacter pylori-negative low-grade gastric MALT lymphoma," World Journal of Gastroenterology, vol. 16, no. 17, pp. 2158-2162, 2010.

[33] A. Stathis, C. Chini, F. Bertoni et al., "Long-term outcome following Helicobacter pylori eradication in a retrospective study of 105 patients with localized gastric marginal zone B-cell lymphoma of MALT type," Annals of Oncology, vol. 20, no. 6, pp. 1086-1093, 2009.

[34] D. Leopardo, G. di Lorenzo, A. de Renzo et al., "Efficacy of rituximab in gastric diffuse large B cell lymphoma patients," World Journal of Gastroenterology, vol. 16, no. 20, pp. 2526-2530, 2010.

[35] E. M. Ibrahim, A. A. Ezzat, M. A. Raja et al., "Primary gastric non-Hodgkin's lymphoma: clinical features, management, and prognosis of 185 patients with diffuse large B-cell lymphoma," Annals of Oncology, vol. 10, no. 12, pp. 1441-1449, 1999.

[36] G. Spectre, D. Libster, S. Grisariu et al., "Bleeding, obstruction, and perforation in a series of patients with aggressive gastric lymphoma treated with primary chemotherapy," Annals of Surgical Oncology, vol. 13, no. 11, pp. 1372-1378, 2006.

[37] E. Zucca and M. Dreyling, "Gastric marginal zone lymphoma of MALT type: ESMO clinical practice guidelines for diagnosis, treatment and follow-up," Annals of Oncology, vol. 21, no. 5, pp. v175-v176, 2010.

[38] S. Cortelazzo, A. Rossi, E. Roggero et al., "Stage-modified international prognostic index effectively predicts clinical outcome of localized primary gastric diffuse large B-cell lymphoma," Annals of Oncology, vol. 10, no. 12, pp. 1433-1440, 1999.

[39] C. Doglioni, M. Ponzoni, A. J. M. Ferreri, and A. Savio, "Gastric lymphoma: the histology report," Digestive and Liver Disease, vol. 43, no. 4, pp. S310-S318, 2011.

[40] A. M. Al-Akwaa, N. Siddiqui, and I. A. Al-Mofleh, "Primary gastric lymphoma," World Journal of Gastroenterology, vol. 10, no. 1, pp. 5-11, 2004. 
[41] M. H. Maor, W. S. Velasquez, L. M. Fuller, and K. B. Silvermintz, "Stomach conservation in stages IE and IIE gastric nonHodgkin's lymphoma," Journal of Clinical Oncology, vol. 8, no. 2, pp. 266-271, 1990.

[42] G. Martinelli, D. Laszlo, A. J. M. Ferreri et al., "Clinical activity of rituximab in gastric marginal zone non-Hodgkin's lymphoma resistant to or not eligible for anti-Helicobacter pylori therapy," Journal of Clinical Oncology, vol. 23, no. 9, pp. 1979-1983, 2005.

[43] A. Avilés, C. Castañeda, S. Cleto et al., "Rituximab and chemotherapy in primary gastric lymphoma," Cancer Biotherapy and Radiopharmaceuticals, vol. 24, no. 1, pp. 25-28, 2009. 


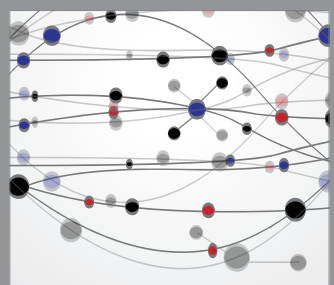

The Scientific World Journal
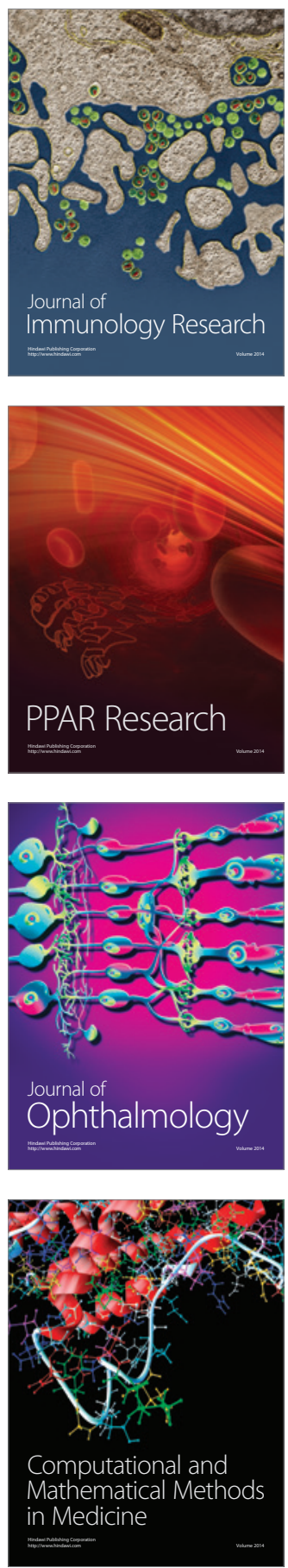

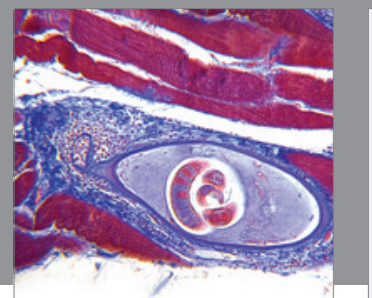

Gastroenterology

Research and Practice
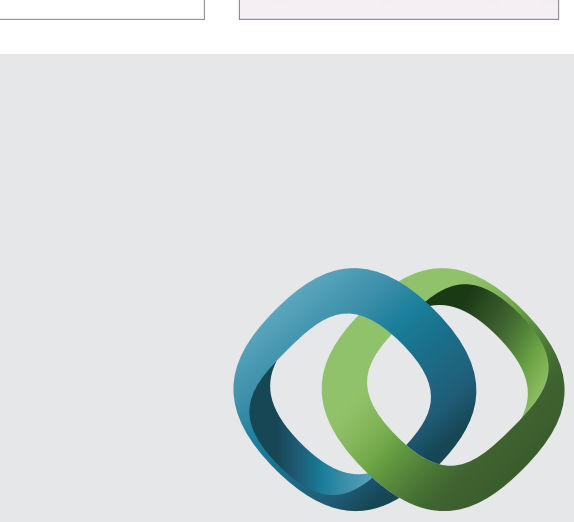

\section{Hindawi}

Submit your manuscripts at

http://www.hindawi.com
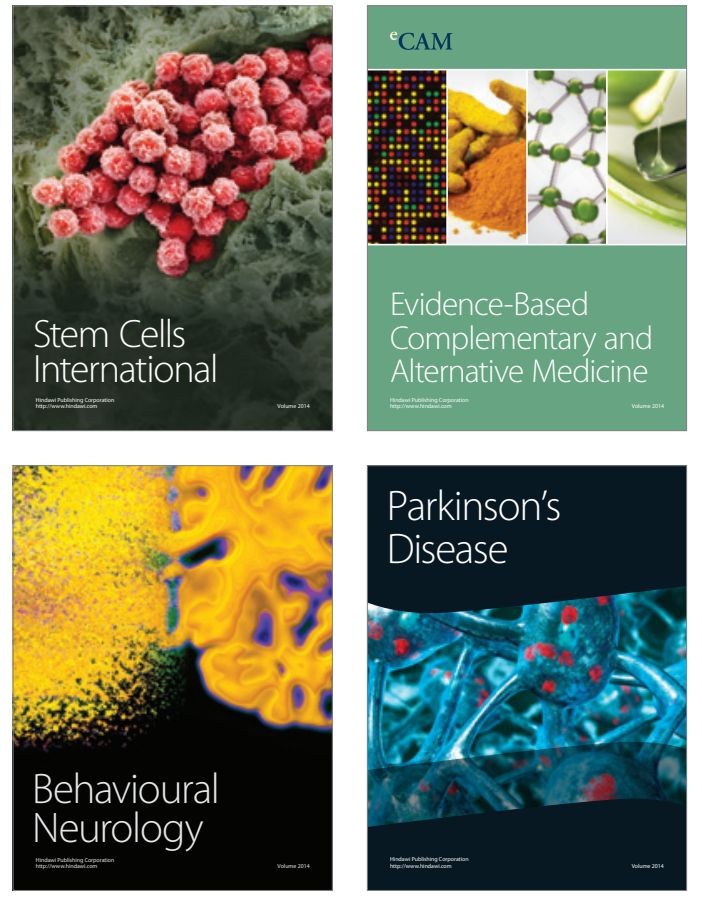
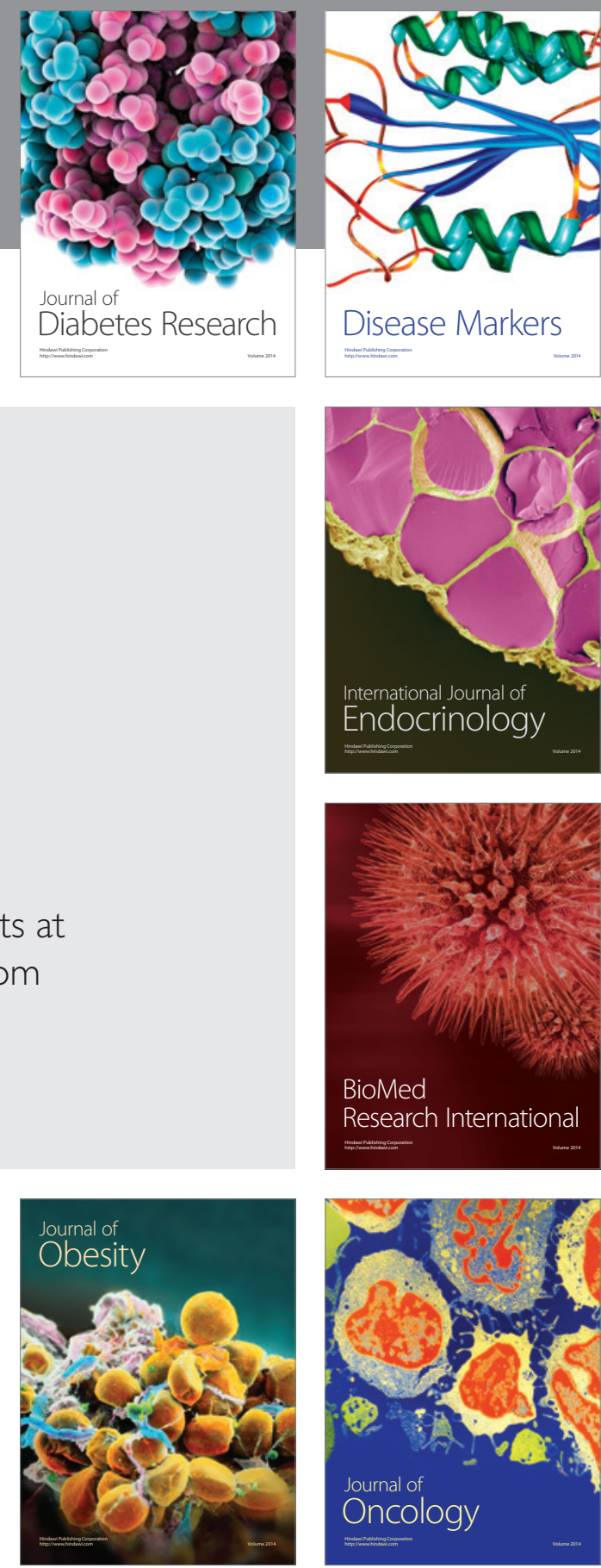

Disease Markers
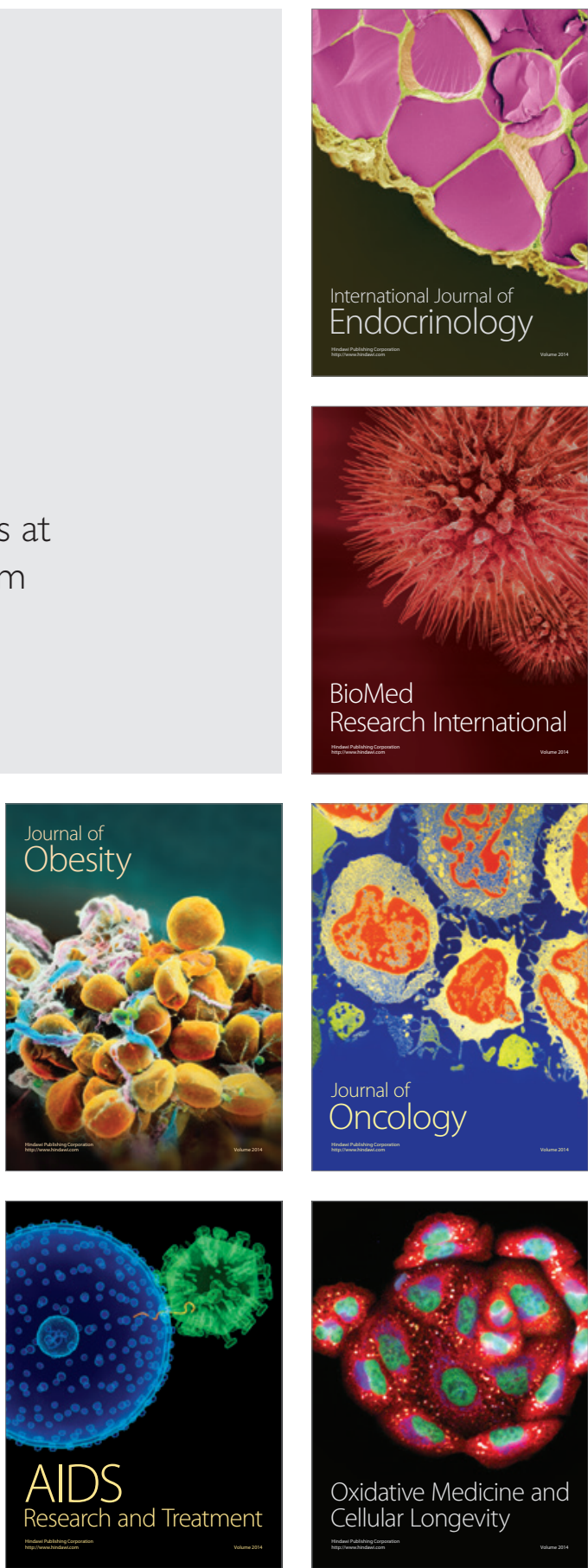